\title{
Quantitative Assessment of Improvement with Single Corticosteroid Injection in Thumb CMC Joint Osteoarthritis?
}

\author{
Munir Khan*, Mohammad Waseem, Ali Raza and Damjana Derham
}

Macclesfield General Hospital, Victoria Road, Macclesfield SK10 3BL, UK

\begin{abstract}
We present a unique prospective study to estimate the median sustained stage-related improvement in pain and hand function in patients with trapezio-metacarpal joint osteoarthritis after administration of a single corticosteroid injection. Response to the corticosteroid injection was assessed using Disability of Arm Shoulder and Hand (DASH) and Visual Analogue Scale (VAS) pain scores. Self assessment scores revealed a reduction in pain and improvement in hand function. All patients reported a significant improvement in pain and hand function $(p \leq 0.05)$, regardless of the disease stage. Additionally, we observed a marked difference in the duration of improvement in hand function between early and late stages of the disease $(p=0.0046)$. In conclusion, it is possible to predict the period of symptomatic improvement at each of the four radiological stages of the disease. This would allow the treating clinician to judge the outcome of treatment with reasonable accuracy.
\end{abstract}

\section{INTRODUCTION}

Carpometacarpal joint osteoarthritis at the base of thumb is a common problem in old age, particularly for women in the fifth to seventh decades. Estimated prevalence of the disease is $8 \%$ to $22 \%$ for women and $2 \%$ to $5 \%$ for men [1, 2]. Severe symptoms are often precipitated by a fall or strain on the wrist, following which the joint may never settle. Non-operative treatment entails splinting, NSAIDs and intraarticular injection of corticosteroids [3, 4], whereas surgical options include ligament reconstruction, excision arthroplasty and joint replacement [5-10]. Several guidelines recommend the use of intra-articular corticosteroids for the management of osteoarthritis. These drugs produce subjective improvement of symptoms in various anatomical regions [11-14] for a few weeks. But there is no consensus on their use, and no simple clinical predictors of response are available at present [15]. Thus, symptomatic relief following corticosteroid use depends on the biological history of individual patients. The use of intra-articular corticosteroids has been advocated in the basal thumb arthritis [5].

The aim of this study was to estimate the improvement in pain and hand function in patients who had a single intraarticular corticosteroid injection for thumb carpometacarpal joint (CMCJ) osteoarthritis.

\section{MATERIALS AND METHODS}

We recruited forty consecutive patients displaying trapezio-metacarpal arthritis who fulfilled the inclusion criteria and consented to take part in the study, from the outpatients clinics. None of the patients had been treated previously with a steroid injection into the joint. Informed consent was obtained from all the participants. All patients received $10 \mathrm{mg}$ of Kenalog $(0.5 \mathrm{ml})$ and a local anaesthetic solution into the joint. Patients were grouped into various

*Address correspondence to this author at the Macclesfield General Hospital, Victoria Road, Macclesfield SK10 3BL, UK;

E-mail: surgeonmunir@hotmail.com stages (I to IV), according to the radiological criteria [16], by three independent surgeons (Fig. 1). In case of dispute, a

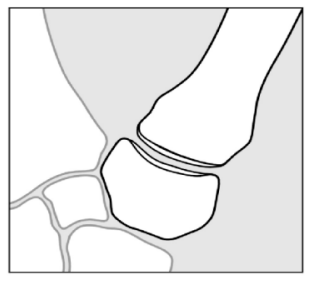

NORMAL
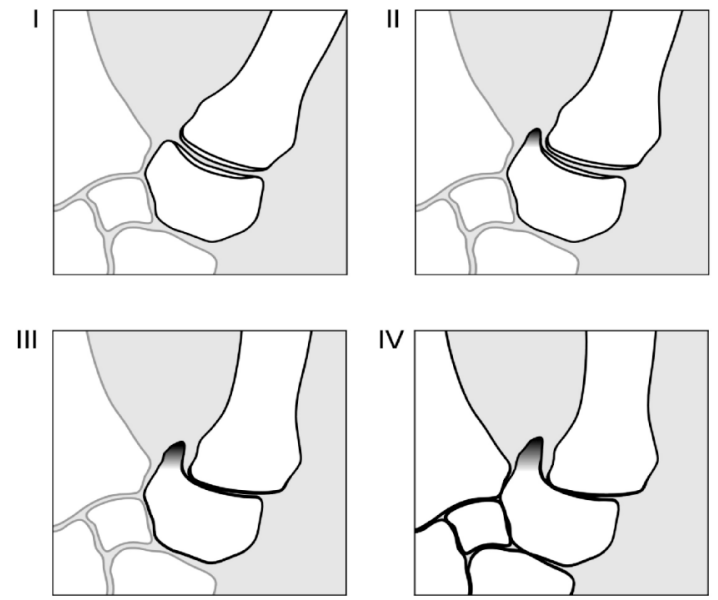

Fig. (1). The Dell's radiological criteria for classification of trapeziometacarpal osteoarthritis. Stage I - Joint space narrowing and subchondral sclerosis but no evidence of subluxation or osteophyte formation. Stage II- Increased subchondral sclerosis and joint space narrowing. Formation of osteophyte at the ulnar border of the trapezium. Metacarpal is subluxated less than $1 / 3^{\text {rd }}$ of the diameter of the base of trapezium. Stage III- Further loss of joint space. More prominent osteophyte at the ulnar border of the trapezium. The metacarpal is subluxated more than $1 / 3^{\text {rd }}$ of base of the trapezium. Stage IV- Total loss of joint space, greater amount of subluxation/dislocation and the presence of pan-trapezial arthritis. 
majority vote was counted. Inter-rater kappa values were calculated to determine consistency between individual surgeons' X-Ray gradings. To establish whether patient groups based on the radiological stages were comparable, we compared gender, age and symptom duration of individuals between the four groups, using the Kruskal-Wallis test (Table 1). Patients were additionally assessed by a physiotherapist at six weeks after the injection.

Table 1. Details of the Four Patient Groups. Values Represent Median and Inter-Quartile Range

\begin{tabular}{|c|c|c|c|}
\hline Group & $\begin{array}{c}\text { Gender } \\
(\mathbf{M} / \mathbf{F})\end{array}$ & $\begin{array}{c}\text { Age } \\
\text { Mean and (IQR) }\end{array}$ & $\begin{array}{c}\text { Mean Duration of } \\
\text { Symptoms (in Months) }\end{array}$ \\
\hline \hline Stage I & $1 / 5$ & $63.4(53-72)$ & 28 \\
\hline Stage II & $5 / 13$ & $64.2(58-78)$ & 39 \\
\hline Stage III & $3 / 7$ & $66.2(57-80)$ & 37 \\
\hline Stage IV & $2 / 4$ & $66.6(59-81)$ & 41 \\
\hline $\mathrm{p}$ value & 0.8 & 0.4 & 0.09 \\
\hline
\end{tabular}

\section{Outcome Measures}

\section{Subjective Improvement in the Hand Function and Pain}

Response was assessed with the aid of the Disability of Arm Shoulder and Hand (DASH) [17] score and a visual analogue score prior to the injection, and six weeks and three to six months post-injection. During every visit, patients were requested to fill in a DASH score and a visual analogue score.

\section{Duration of the Symptomatic Improvement}

Patients were additionally asked to provide information on the duration of symptomatic improvement after the corticosteroid injection. The duration of symptomatic improvement was recorded on the basis of the patient's memory.

\section{Statistical Analysis}

At six weeks post-injection, improvement scores in hand function and pain were compared to pre-injection scores using the Wilcoxon signed-rank test for two related samples. Similarly, the DASH scores at six weeks were compared to three months and six months scores. Differences in improvement of hand function and pain at the early (I \& II) and late (III \& IV) stages of the disease were compared with the Mann-Whitney independent sample test. The DASH scores in Stage I and II patients were separately compared with those of Stage III and IV patients respectively, to overcome inaccuracies due to overlap between Stages II and III.

The Kaplan-Meier method was applied to estimate the median duration of sustained improvement at each stage of the disease, with 95\% confidence intervals. The log-rank (MantelCox) test was performed to establish whether patient groups categorised on the basis of radiological grade differed in terms of the duration of symptomatic improvement.

\section{RESULTS}

Forty patients were analysed, including 29 females and 11 males. Patient ages ranged from 53 to 81 years, with a mean age of 65.1 years. No patients were lost to follow-up. The symptom duration period ranged from 3 months to over five years, with a mean duration of 36 months. Six patients were diagnosed with stage I disease, eighteen with stage II disease, ten with stage III disease, and six with stage IV disease.

\section{Radiological Grading of the Disease}

There was moderate (weighted kappa: 0.58) to good (weighted kappa: 0.71) inter-rater agreement for the radiological grading of the disease.

\section{Subjective Outcome (DASH and VAS Scores)}

Pre-injection visual analogue and DASH scores are presented in Table 2. At six weeks, twenty-six patients displayed a DASH score improvement of at least ten points. Four patients showed an improvement of lower than ten points, while DASH scores deteriorated in ten patients. At six weeks, reduction in the pain (visual analogue score) was evident in all but two patients. Pre-injection visual analogue scores were significantly higher (median $=7$ ) than those recorded at six weeks (median $=3)(\mathrm{T}=0, p \leq 0.05, \mathrm{r}=-0.82)$. Similarly, the DASH score at six weeks (median $=43$ ) was a significant improvement in all patients, in relation to the pre-injection DASH score $($ median $=57.5)(\mathrm{T}=0, p \leq 0.05, \mathrm{r}=-0.72)$. A significant deterioration was noticed in DASH scores in all patients, at three months (median 46) and six months (median $52)$, as compared to six weeks stage (median 43$)(\mathrm{p}=<0.05)$ (Fig. 3).

Table 2. Baseline Function (DASH) and Pain (VAS) Scores at Different Stages of the Disease. Values Represent Medians and Inter-Quartile Ranges

\begin{tabular}{|c|c|c|}
\hline $\begin{array}{c}\text { Stage of the } \\
\text { Disease }\end{array}$ & $\begin{array}{c}\text { Pre-Injection } \\
\text { DASH Scores }\end{array}$ & $\begin{array}{c}\text { Pre-Injection } \\
\text { VAS Scores }\end{array}$ \\
\hline \hline I & $44(32-64)$ & $6(5-7)$ \\
\hline II & $52(44-66)$ & $6(5-8)$ \\
\hline III & $66(40-75)$ & $7(6-8)$ \\
\hline IV & $74(54-91)$ & $8(7-9)$ \\
\hline
\end{tabular}

Stage-related improvement in pain (VAS) is presented in Table 4. At six weeks, the visual analogue score improvement in patients diagnosed with early stages (I \& II) of the disease (median $=3$ ) was not significantly different from patients in later stages (III \& IV) of the disease (median $=2),(U=130, p=0.08, r=-0.26)$. At six weeks the improvement in DASH scores in early-stage patients (median $=14.5)$ was comparable to those in late-stage patients $($ median $=8.5),(\mathrm{U}=127, \mathrm{p}=0.07, \mathrm{r}=-0.28)$. Moreover, at six weeks, the DASH score improvement in Stage I disease patients (median $=14.5$ ) was comparable to that in Stage III disease patients (median $=4.5)(\mathrm{U}=130, p$ $=0.09, \mathrm{r}=-0.25)$. Similarly, the DASH score improvement in Stage II disease patients (median $=14.5$ ) was analogous to that in Stage IV disease patients (median $=8.4)(\mathrm{U}=143, p$ $=0.08, \mathrm{r}=0.27$ ).

However, at three months and six months (Fig. 3) the DASH score in the early-stage patients (median $=8$ ) was 
significantly different from the late-stage patients (median $=$ $1.5),(\mathrm{U}=50, \mathrm{p}=<0.05, \mathrm{r}=-0.61)$.

\section{Duration of Symptomatic Improvement}

Despite the comparable subjective improvement in hand function and pain between early and late stages of the disease at six weeks, there were significant differences $(p=$ 0.0046) in the duration of symptomatic improvement (Table 3, Fig. 2). The duration of median sustained improvement in Stage I patients was 17 weeks. Most patients with stage II disease still reported improved hand function, at six months post-injection. In contrast, the reported median sustained improvement in Stage III and IV patients was only four weeks.

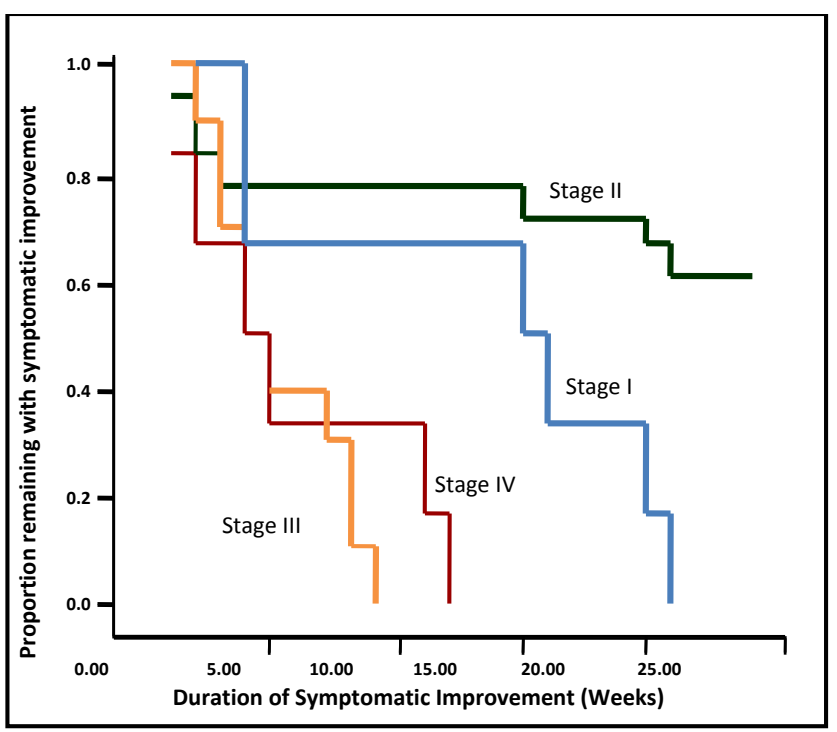

Fig. (2). Kaplan-Meier curve showing the duration of symptomatic improvement at each stage of the disease.

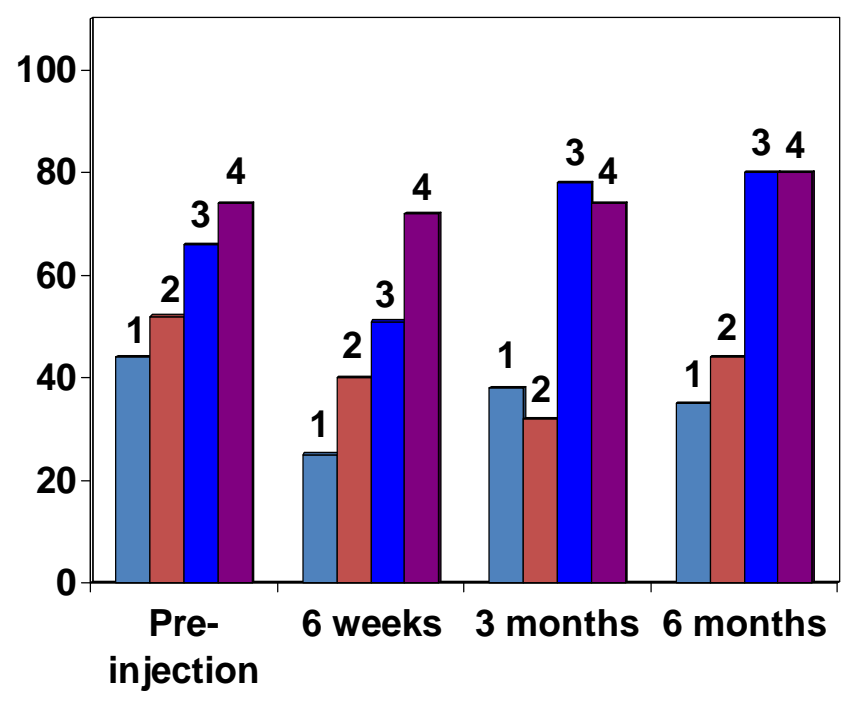

Fig. (3). DASH score in different radiological stages of the disease (Error bars show median \& 95\% Confidence intervals).

\section{DISCUSSION}

This is a patient oriented study of the subjective improvement in pain and hand function following a single intra-articular injection of corticosteroid, for basal thumb

Table 3. Median Duration of Symptomatic Improvement at Each Stage of the Disease

\begin{tabular}{|c|c|c|}
\hline $\begin{array}{c}\text { Stage of } \\
\text { the Disease }\end{array}$ & $\begin{array}{c}\text { Median Duration of } \\
\text { Symptomatic Improval (Weeks) }\end{array}$ & $\mathbf{9 5 \%}$ CI \\
\hline \hline I & 17 & $(13,21)$ \\
\hline II & $>50 \%$ were still improved at 6 months. & - \\
\hline III & 4 & $(2,6)$ \\
\hline IV & 4 & $(2,6)$ \\
\hline
\end{tabular}

Table 4. Summary of the Changes in DASH AND Pain (VAS) Scores at Six Weeks, Compared to Pre-Injection Measures at Each Stage of the Disease. Values Represent Median and Inter-Quartile Range

\begin{tabular}{|c|c|c|}
\hline $\begin{array}{c}\text { Stage of } \\
\text { Disease }\end{array}$ & $\begin{array}{c}\text { Improvement in } \\
\text { DASH Score }\end{array}$ & $\begin{array}{c}\text { Improvement in } \\
\text { VAS Score }\end{array}$ \\
\hline \hline I & $14.5(8-19)$ & $4.0(2-5)$ \\
\hline II & $14.5(12-16)$ & $3.0(3-7)$ \\
\hline III & $4.5(-6-15)$ & $2.5(2-4)$ \\
\hline IV & $8.4(2-19)$ & $2.5(0-6)$ \\
\hline
\end{tabular}

arthritis. Our results showed that significant improvement in pain and hand function in patients with osteoarthritis of the thumb CMC joint can be achieved with a single corticosteroid injection. While the level of improvement achieved at six weeks was not related to the radiological stage, the duration of symptomatic improvement varied significantly, depending on the disease stage. This finding has two important implications. Firstly, corticosteroids improve pain and hand function, irrespective of the disease stage, and secondly, treatment with these drugs only provides long-term benefit at initial stages of the disease (I or II). At higher stages (III or IV), intra-articular corticosteroids may only be effective in patients awaiting definite surgical intervention. Furthermore, there was good inter-rater agreement for radiological staging of the disease using the Dell radiological criteria. Thus, we believe that our results can be easily reproduced in another clinical setting.

There are two limitations to our study. Firstly, we did not use fluoroscopy to ensure intra-articular delivery of corticosteroids. However, all injections were administered by an experienced physiotherapist. Moreover, the avoidance of fluoroscopy ensures that our results are more widely applicable, as fluoroscopy units are not generally available in outpatient departments. Secondly, relatively few patients with stage I disease were enrolled in the study, which may explain the unexpectedly short duration of symptomatic improvement, compared to stage II of the disease.

Day and colleagues [18] reported mean improvement for 23 months with a single intra-articular corticosteroid injection in stage I disease. Only $35 \%$ of patients with stage II and III disease displayed sustained improvement. 
Compared to their results, our stage I patients reported improvement for a shorter duration. However, it is important to note that patients in the earlier study wore splints, which made it difficult to estimate the improvement attributable to corticosteroid alone. Some patients in our study used splints, but were not requested to change their practice. We believe that this is a better way of estimating the effects of the intraarticular corticosteroid, as the patient's baseline status is left undisturbed.

In conclusion, stage I disease patients had sustained symptomatic improvement for 17 weeks, although the true duration is possibly between 13 and 21 weeks. Most stage II patients still report improvement at 6 months post-injection. Stage III and IV patients had an identical prognosis of 4 weeks, although the true duration may be between 2 and 6 weeks. The findings of this unique study should allow the treating clinician to confidently predict the outcome of an intra-articular corticosteroid injection in patients presenting with thumb CMC joint osteoarthritis.

\section{ACKNOWLEDGEMENT}

The authors would like to thank Mr. Andy Biggs in photography department of The RJAH for producing illustration of the Dell's radiological criteria.

\section{REFERENCES}

[1] Aune S. Osteo-arthritis in the first carpo-metacarpal joint; an investigation of 22 cases. Acta Chir Scand 1955; 109(6): 449-56.

[2] Kelsey JP, Kreiger H, Harris N, Chernow C. Upper extremity disorders: a survery of their frequency and cost in the United States. St Louis: CV Mosby 1980.

[3] Pomerance JF. Painful basal joint arthritis of the thumb. Part I: anatomy, pathophysiology, and diagnosis. Am J Orthop 1995; 24(5): 401-8.

[4] Carr MM, Freiberg A. Osteoarthritis of the thumb: clinical aspects and management. Am Fam Physician 1994; 50(5): 995-1000.
[5] Pellegrini VD, Jr. Osteoarthritis at the base of the thumb. Orthop Clin North Am 1992; 23(1): 83-102.

[6] Lane LB, Eaton RG. Ligament reconstruction for the painful "prearthritic" thumb carpometacarpal joint. Clin Orthop Relat Res 1987; (220): 52-7.

[7] Pellegrini VD, Jr, Burton RI. Surgical management of basal joint arthritis of the thumb. Part I: long-term results of silicone implant arthroplasty. J Hand Surg 1986; 11(3): 309-24.

[8] Eaton RG, Lane LB, Littler JW, Keyser JJ. Ligament reconstruction for the painful thumb carpometacarpal joint: a longterm assessment. J Hand Surg 1984; 9(5): 692-9.

[9] Raven EE, Kerkhoffs GM, Rutten S, Marsman AJ, Marti RK, Albers GH. Long term results of surgical intervention for osteoarthritis of the trapeziometacarpal joint: comparison of resection arthroplasty, trapeziectomy with tendon interposition and trapezio-metacarpal arthrodesis. Int Orthop 2007; 31(4): 547-54.

[10] Pellegrini VD, Jr, Burton RI. Surgical management of basal joint arthritis of the thumb. Part II: ligament reconstruction with tendon interposition arthroplasty. J Hand Surg 1986; 11(3): 324-3.

[11] Leveaux VM, Quin CE. Local injection of hydrocortisone and procaine in osteo-arthritis of the hip joint. Ann Rheum Dis 1956; 15(4): 330-7.

[12] Kehr MJ. Comparison of intra-articular cortisone analogues in osteo-arthritis of the knee. Ann Rheum Dis 1959; 18: 325-8.

[13] Raynauld JP, Buckland-Wright C, Ward R, et al. Safety and efficacy of long-term intraarticular steroid injections in osteoarthritis of the knee: a randomized, double-blind, placebocontrolled trial. Arthritis Rheum 2003; 48(2): 370-7.

[14] Bellamy N, Campbell J, Robinson V, Gee T, Bourne R, Wells G. Intraarticular corticosteroid for treatment of osteoarthritis of the knee. Cochrane Database Syst Rev 2006; (2): CD005328.

[15] Jones A, Doherty M. Intra-articular corticosteroids are effective in osteoarthritis but there are no clinical predictors of response. Ann Rheum Dis 1996; 55(11): 829-32.

[16] Dell PC, Brushart TM, Smith RJ. Treatment of trapeziometacarpal arthritis: results of resection arthroplasty. J Hand Surg 1978; 3(3): 243-9.

[17] Jester A, Harth A, Wind G, Germann G, Sauerbier M. Disabilities of the arm, shoulder and hand (DASH) questionnaire: determining functional activity profiles in patients with upper extremity disorders. J Hand Surg [Br] 2005; 30(1): 23-8.

[18] Day CS, Gelberman R, Patel AA, Vogt MT, Ditsios K, Boyer MI. Basal joint osteoarthritis of the thumb: a prospective trial of steroid injection and splinting. J Hand Surg 2004; 29(2): 247-51. 